\title{
UMA NOVA ESPÉCIE DE ACHYROCLINE (LESS.) DC. (ASTERACEAE) DO RIO GRANDE DO SUL (BRASIL) ${ }^{1}$
}

\author{
LEONARDO PAZ DEBLE²
}

\section{RESUMO}

É descrita e ilustrada uma nova espécie de Asteraceae: Achyrocline luisiana Deble. Reconhecida como próxima a Achyrocline eriodes (Mattf.) Deble \& Marchiori e A. marchiorii Deble, a espécie tem ocorrência restrita ao Estado do Rio Grande do Sul. É fornecida uma chave para a separação das espécies sul-brasileiras de Achyrocline.

Palavras-chave: Achyrocline luisiana, nova espécie, Gnaphalieae, Asteraceae.

\section{ABSTRACT}

In the present paper, it is described and illustrated a new species of Asteraceae: Achyrocline luisiana Deble. Close to Achyrocline eriodes (Mattf.) Deble \& Marchiori and A. marchiorii Deble, the new species is known only for the State of Rio Grande do Sul (Brazil). A key is furnished to set apart the southern-brazilian species of Achyrocline.

Key words: Achyrocline luisiana, new species, Gnaphalieae, Asteraceae.

\section{INTRODUÇÃO}

Achyrocline (Less.) DC. é um gênero afroamericano, composto por aproximadamente 45 binômics válidos. Na América do Sul, são em número de 35 as espécies, concentradas, sobretudo, em regiões subtropicais e tropicais de altitude, como nos campos e cerrados do Brasil. Com a presente descrição, eleva-se a nove, o número de espécies sul-brasileiras.

\section{DESCRIÇÃO}

\section{Achyrocline luisian،. Deble, sp. nov. ${ }^{3}$}

Suffrutex ramosus, lignosus, $60-80 \mathrm{~cm}$ altus; caulibus ascendentibus erectisve, teretibus, ramosis, dense griseotomentosis. Folia alterna (internodiis 0,5-1,5 cm longis). sessilia, eliiptica, integra, trinervata, grisco-tomentosa, apice acuta ad obtusa, basi in pseudopetiolum attenuata, superne gradatim minora, 2-6 cm longa, 0,5-1,5 cm lata. Capitula multa, lutei, cymoso-corymbosa glomerata disposita. Involucrum cylindraceum, 3,5-4 mm altum, 1,5$2 \mathrm{~mm}$ crassum. Bracteis involucralibus 8-9, hyalinis, citrinis; externis ovatis, obtusis, 2,5-3 mm longis, $1,5 \mathrm{~mm}$ latis, dorso dense lanoso, stereomate $0,5 \mathrm{~mm}$ alto; mediis oblongis, obtusis, 3,2 mm longis, 1,2 num latis, dorso cum pilis lanosis et glandulosis, stereomate $1-1,2 \mathrm{~mm}$ alto; interioribus oblongo-spathulatis, subtruncatis, 3,5-3,8 mm iongis, $0,8 \mathrm{~mm}$ latis, dorso cum pilis glandulosis, stereomate 1,5-1,8 $\mathrm{mm}$ alto. Flores lutei, dimorphi: n:arginales 1-2, feminei, corolla filiforme, 2,8 mm longa, apice 4-dentata, dentibus deltoides, 0,04 mm longis, cum p:! lis glandulosis; stylo 2,5 mm longo; rami cum 0,8 mm, $a_{i}$ ice truncati, papillosi; flores disci 4, hermaphroditi, corolla tubulosa, 2,6-2,8 mm longa, 5-dentata, dentibus deltoides, $0,15 \mathrm{~mm}$ longis, cum pilis glandulosis; antherae 1,3 mm longae, caudatae; caudue elongatce, barbatae, apice oblongo-trigonae, subacutae. Achicnia ovata, castanea, leviter papilosa, 0,8 mm longa, 0,3 mm lata. Pappus albus, setae $3 \mathrm{~mm}$ longae; cellulis apicalibus subclavatis, basi patentibus.

Subarbusto ramoso, lenhoso, ascendente ou ereto, densamente gríseo-tomentoso, de 60-80 $\mathrm{cm}$ de altura (Figura 1a). Folhas alternas (entrenós đe 0,5-1,5 cm), sésseis, elípticas, trinervadas, íntegras, de $2-6 \mathrm{~cm}$ de comprimento por $0,5-1,5 \mathrm{~cm}$ de largura, concolores, densamente gríseo-tomentosas em ambas as faces, com ápice agudo até obtuso e base atenuada em

1 Artigo recebido em 10/05/2005 e aceito para publicação em 5/7/2005.

2 Biólogo, Msc., bolsista da CAPES, doutorando do Programa de Pós-Graduação em Engenharia Florestal, Centro de Ciências Rurais, Universidade Federal de Santa Maria, CEP 97105-900, Santa Maria (RS).deble.biol@bol.com.br

3 Dedico esta espécie ao amigo Luis Alberto Bortolucci Geyer. 


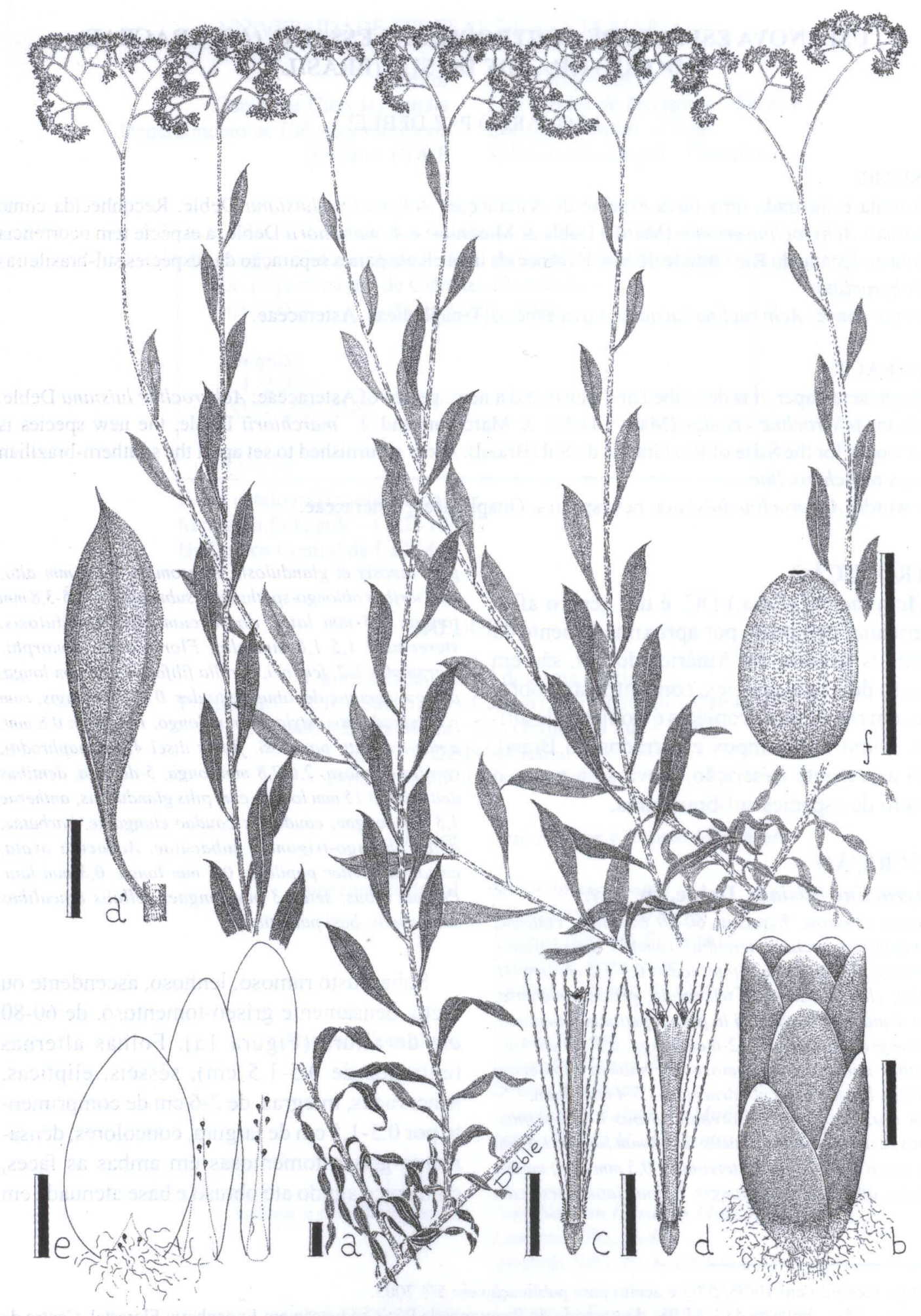

FIGURA 1 - Ramo de Achyrocline luisiana (a). Folha (a'). Capítulo (b). Flor marginal (c). Flor do disco (d). Brácteas involucrais (e). Aquênio (f). Escala a, a' $=1 \mathrm{~cm} ; \mathrm{b}, \mathrm{c}, \mathrm{d}, \mathrm{e}, \mathrm{f}=1 \mathrm{~mm}$. 
pseudopecíolo (Figura 1a'). Capítulos numerosos, amarelos, dispostos em cimas de glomérulos, compondo corimbos mais ou menos contraídos (Figura 1a). Invólucro cilíndrico, de 3,5-4 mm de altura por 1,5-2 $\mathrm{mm}$ de diâmetro (Figura 1b). Brácteas involucrais, 8-9; as externas, ovadas, de ápice obtuso no ápice $\mathrm{e}$ dorso densamente coberto de pêlos lanosos, com 2,5-3 $\mathrm{mm}$ de comprimento por $1,5 \mathrm{~mm}$ de largura e estereoma de $0,5 \mathrm{~mm}$ de altura (Figura 1e); as medianas, oblongas ( $3,2 \mathrm{~mm}$ de comprimento por $1,2 \mathrm{~mm}$ de largura) e obtusas no ápice, com pêlos lanosos e glandulares no dorso, e estereoma de 1-1,2 mm de altura (Figura 1e); as internas, oblongo-espatuladas $(3,5-3,8 \mathrm{~mm}$ de comprimento, por $0,8 \mathrm{~mm}$ de largura) e subtruncadas no ápice, com pêlos glandulares no dorso e estereoma de 1,5-1,8 $\mathrm{mm}$ de altura (Figura 1e). Flores amarelas, dimorfas. Flores marginais, 1-2, femininas, filiformes, com corola de 2,8 $\mathrm{mm}$ de comprimento e ápice 4-dentado (Figura 1c); dentes deltóides (0,04 mm), com pêlos glandulares (Figura 1c); estigma de 2,5 $\mathrm{mm}$ de comprimento, com ramas de $0,8 \mathrm{~mm}$, truncadas e papilosas no ápice. Flores do disco, 4 , hermafroditas, com corola de 2,6-2,8 $\mathrm{mm}$ de comprimento, 5-dentada no ápice (Figura 1d); dentes deltóides $(0,15 \mathrm{~mm})$, com pêlos glandulares (Figura 1d); anteras de 1,3 mm, com cau- das fimbriadas, alongadas e de ápice oblongo, triangular, levemente agudo. Aquênios ovados, de $0,8 \mathrm{~mm}$ de comprimento por $0,3 \mathrm{~mm}$ de largura (Figura 1f). Pápus branco, de $3 \mathrm{~mm}$, com células apicais subclavadas e células basais patentes.

TIPO - BRASIL, Rio Grande do Sul, Sapucaia do Sul, morro Sapucaia, flores amarelas, comum no topo do morro, 290 m.s.m., I. Fernandes 637, 26.XI.1989. Holotypus ICN.

Distribuição \& Habitat: Conhecida apenas para a localidade típica: o morro Sapucaia, em Sapucaia do Sul (RS). Floresce durante a primavera.

Comentários: Achyrocline luisiana demonstra relação com Achyrocline eriodes (Mattf.) Deble $\&$ Marchiori, da qual difere pelas folhas atenuadas na base, bem como pela cor e número menor de brácteas no invólucro. De Achyrocline marchiorii Deble, separa-se pelas brácteas involucrais obtusas até truncadas no ápice, assim como pelas flores hermafroditas em número maior do que as femininas. De Achyrocline heringeri (H. Rob.) Deble \& Marchiori, separa-se pelos capítulos distintamente menores e pela presença de uma ou duas flores femininas no capítulo.

\section{CHAVE DICOTÔMICA:}

As espécies sul-brasileiras de Achyrocline podem ser identificadas pela seguinte chave dicotômica:

1a. Folhas longamente decurrentes; talos alados 2

2a. Folhas lineares até linear-lanceoladas $(5-13 \mathrm{~cm}$ de comprimento por $0,3-0,8 \mathrm{~cm}$ de largura), apenas com a nervura principal evidente; parte adaxial da folha, com pêlos lanosos de células basais diminutas, inconspícuas em conjunto $(-0,02 \mathrm{~mm})$, e célula terminal persistente, em forma de látigo; parte abaxial, densamente lanosa

1. Achyrocline alata (H.B.K.) DC.

2b.Folhas lanceoladas até elípticas (3-6 cm de comprimento por 0,5-1,8 cm de largura), com todas as nervuras evidentes; parte adaxial da folha com pêlos lanosos de células basais conspícuas em conjunto $(+0,05 \mathrm{~mm})$ e célula terminal caduca, em forma de látigo, conferindo ao limbo foliar uma textura áspera; parte abaxial, escassamente lanosa 
1b. Folhas não decurrentes ou breve-decurrentes; talos sem alas

3a. Brácteas involucrais agudas no ápice

4a. Plantas densamente incano-tomentosas. Brácteas involucrais, 12-13

3. Achyrocline marchiorii Deble

4b. Plantas gríseo-tomentosas até laxamente tomentosas. Brácteas involucrais, 8-10 . 5

5a. Invólucro de 5-6 mm de altura. Brácteas involucrais externas, agudo-acuminadas 4.Achyrocline flaccida (Weinm.) DC.

5b. Invólucro de 3-4 mm de altura. Brácteas involucrais externas, levemente agudas até obtusas 5. Achyrocline tomentosa Rusby, p.p.

3b.Brácteas involucrais obtusas no ápice 6

6a. Flores hermafroditas, em maior número que as femininas. 6. Achyrocline luisiana Deble

6b. Flores hermafroditas, em número igual ou menor do que as femininas 7

7a. Folhas lineares, linear-lanceoladas ou oblongo-lineares, de até $5 \mathrm{~mm}$ de largura 8

8a. Folhas lineares ou linear-lanceoladas, de 10-60 mm de comprimento por 1-5 mm de largura. Capítulos cilíndricos, de 4-6 mm de altura por 1-1,5 mm de diâmetro; flores femininas, 3-6

7. Achyrocline satureioides (Lam.) DC.

8b. Folhas oblongo-lineares, de 10-25 mm de comprimento por 1,5-2,5 mm de largura. Capítulos oblongos, de 6,5-7 mm de altura por 2,5-3 mm de diâmetro; flores femininas, 8-10

8. Achyrocline crassiuscula (Malme) Deble \& Marchiori

7b. Folhas lanceoladas até elípticas, de 4-20 mm de largura 9

9a. Invólucro marfim ou creme, de 3-4 mm de altura. Brácteas involucrais, 8-9, todas mais ou menos do mesmo tamanho. Flores femininas, 4; hermafroditas, 1-2

5. Achyrocline tomentosa Rusby, p.p.

9b. Invólucro amarelo, de 4,5 mm de altura. Brácteas involucrais, 9-11, as externas, alcançando apenas $1 / 2$ do comprimento das internas. Flores femininas, 3-4; hermafroditas, 2-4

9. Achyrocline anabelae Deble

\section{BIBLIOGRAFIA}

Deble, L. P. Novas espécies de Achyrocline (Less.)

DC. para o sul do Brasil. Balduinia, Santa Maria, n. 3, p. 5-9, 2005.

Deble, L. P., Marchiori, J. N. C. Novidades em Achyrocline (Less.) DC. (Asteraceae Gnaphalieae). Balduinia, Santa Maria, n. 3, p. 10-13, 2005.
Deble, L. P., Marchiori, J. N. C. Redução de Stenophalium A. Anderb. à sinonímia de Achyrocline (Less.) DC. (Asteraceae Gnaphalieae). Balduinia, Santa Maria, n. 4, p. 10-19, 2005.

Giangualani, R. N. Las especies argentinas del género Achyrocline (Compositae). Darwiniana, San Isidro, v. 20, n. 3-4, p. 549-576, 1976. 